Portland State University

PDXScholar

Center for Public Service Publications and

Reports

Center for Public Service

$10-2005$

\title{
Explicating Factors that Foster Civic Engagement among Students
}

\author{
Masami Nishishiba \\ Portland State University, nishism@pdx.edu \\ Hal T. Nelson \\ Portland State University, hnelson@pdx.edu \\ Craig Shinn \\ Portland State University
}

Follow this and additional works at: https://pdxscholar.library.pdx.edu/publicservice_pub

Part of the Higher Education Commons, and the Public Affairs, Public Policy and Public Administration Commons

Let us know how access to this document benefits you.

\section{Citation Details}

Nishishiba, Masami, Hal T. Nelson, and Craig W. Shinn. "Explicating Factors That Foster Civic Engagement Among Students". Journal of Public Affairs Education 11.4 (2005): 269-285.

This Article is brought to you for free and open access. It has been accepted for inclusion in Center for Public Service Publications and Reports by an authorized administrator of PDXScholar. Please contact us if we can make this document more accessible: pdxscholar@pdx.edu. 


\title{
Explicating Factors that Foster Civic Engagement among Students
}

\author{
Masami Nishishiba, Hal T. Nelson, and Craig W. Shinn \\ Portland State University
}

\begin{abstract}
This paper investigates many facets of civic engagement by analyzing how college undergraduate students conceptualize civic engagement and by examining factors that predict greater student involvement in political, social, and community affairs. We administered a survey to college students at the beginning of fall, winter, and spring terms, 2001-02. We analyzed survey responses using a structural equation modeling (SEM) technique. The analysis examines how expectations of community and political efficacy, attitudes regarding citizen control of government, and attitudes toward diversity relate to the students' civic engagement behaviors such as monthly volunteer hours, organizational participation, advocacy, voting, direct political action, and action to promote diversity and social justice in the community. The result of the SEM analysis indicates that expectations of efficacy significantly predict students' direct political action, monthly volunteer hours, organizational participation, advocacy, and voting attitude. Students' sense of control over public affairs significantly predicts organizational participation, advocacy, and voting attitude. The implications of these results are discussed in relation to curriculum design to foster civic engagement.
\end{abstract}

J-PAE 11 (2005):4:269-285
Citizen participation and engagement in public life are essential elements of democracy. Successful democratic society requires citizens to actively engage in community development and participate in community problem-solving. Many argue that democracy requires a culture that fosters a strong sense of civic responsibility among citizens. (Battistoni, 1997; Boyte and Farr, 1997). Consequently, the decrease in civic engagement among U.S. citizens during recent decades is a concern. Both the academic and popular press (Barber, 1999; Skocpol and Fiorina, 1999; New York Times, 2000; Putnam, 2000; Skocpol, 2003) have warned that the decline in civic engagement, left unchecked, can pose a major threat to a democratic society.

During the last decade, postsecondary educators began taking this concern seriously. The notion that one of the responsibilities of higher education is to prepare students for citizenship prompted educators to look into ways to strengthen civic education. Universities across the nation developed curricula specifically designed to cultivate good citizenship and to promote civic engagement (Checkoway, 2001; Ehrlich, 2000; Morgan et al., 2002). They began experimenting with service learning, an approach that combines community experience with classroom instruction and reflection. Under the service learning curricular model, students participate in variety of community activities, while instructors guide the students to put their experience into some larger academic context.The service learning movement has gained momentum, and now universities, community colleges, and high schools incorporate service learning into their curriculum and encourage civic engagement among students.

The assumption underlying the pedagogy of service learning is that good citizenship not only consists of participating in the formal political process but also involves participating in various voluntary organizations that contribute to the civic good of the community. Active participation in the community is a way to cultivate good citizenship and democracy. For this reason, it is not surprising to see heightened interest among public affairs educators in service learning. Dicke, Dowden, and Torres (2004) note the increase in service learning courses in the public affairs curriculum because 


\section{Explicating Factors That Foster Civic Engagement among Students}

the "goals of service learning are often congruent with the missions of Master of Public Administration programs and the learning objectives in courses on civic engagement or political activism" (199).

As new content and learning methods intended to stimulate civic engagement among young people developed, the need for a more systematic evaluation of the impact and effect of these educational efforts became evident. For example, some have argued that there is little evidence to suggest that developing civic and political knowledge actually leads to an increased level of civic engagement (Alt and Medrich, 1994; Hamilton and Zeldin, 1987). Rothstein (New York Times, 2001) claimed that there is no research that provides evidence that students who know more about civics and history are more likely to vote. The service learning approach, which immerses students more directly into community engagement activities, has not escaped criticism. Myers-Lipton (1999) pointed out that service learning advocacy is not grounded in objective research. Little research has been carried out to explicate the posited pathway between interning in a food bank and voting in elections, for example.

One major purpose of this project is to help fill this vacuum in the research on civic engagement strategies and their relative effectiveness. This study contributes to the field of civic education by disaggregating how college students conceptualize civic engagement and by defining variables predicting greater student involvement in political, social, and community affairs. The results of this research reinforce our agreement with Bok (2001), who asserted that developing a more informed, deliberative, and active citizenry requires adopting a holistic strategy that will make a lasting difference. Our approach begins by identifying specific factors that contribute to different aspects of civic engagement.

\section{Components of Civic Engagement}

Ehrlich (2000) defined civic engagement broadly as citizen behavior "working to make a difference in the civic life of our communities and developing the combination of knowledge, skills, values, and motivation to make that difference" (vi). When people find opportunities to make a difference in their communities and act to make the world a better place, we consider them engaged citizens. This general definition encompasses a variety of individual behaviors and roles. Different aspects of civic engagement, however, are highlighted by different scholars. Commonly mentioned components of civic engagement include advocacy, taking direct action, actively participating in an organization or association, volunteering, and voting in an election.

Advocacy. Civic engagement is evident when people express their ideas and concerns to government officials and public media. In a study conducted by Keeter et al. (2002), 23 percent of the respondents $(\mathrm{N}=3,246)$ reported that they had at some point in their lives signed a petition to change policy or practices of their government or other groups; 18 percent of the respondents had contacted or visited public officials at some level of government.

Taking direct action. Some people do more than write their concerns to public officials or the media in order to have their voices heard. They engage in direct action to make social change. Participating in a protest or a demonstration to express ideas or participating in boycotts are two examples. Keeter et al. (2002) report that 38 percent of their respondents engaged in boycotting a product from a certain company as a way of protesting the company's conduct; 4 percent reported participating in a protest event.

Organizational participation. People also engage in civic and social issues through activities and membership in organizations and associations. Noted with surprise by French observer Alexis de Toqueville, this form of engagement has a long and proud tradition in U.S. civic life. Organizations and associations continue to play an important role in U.S. democracy. Skocpol (1999) observes that organizations and voluntary associations "mediate between government and society, empower participating citizens, and embody relationships between leaders and supporters" (461). Keeter et al. (2002) view participation in organizations and associations as an indicator of civic engagement. They found that 31 percent of their respondents actively participated in a group or association. 


\section{Explicating Factors That Foster Civic Engagement among Students}

Volunteering. Volunteering for organizations and community groups is a common way for citizens to engage in issues that concern them (Putnam, 2000; Putnam and Feldstein, 2003; Skocpol and Fiorina, 1999). One study estimated that as much as half the U.S. population gives time to the community by volunteering; still, contemporary volunteering has become episodic, with a general tendency to spend "an evening a week on an activity for a few months as time permits, rather than having to make a longterm commitment to an organization" (Wuthnow, 1998, 79).

Voting. Voting allows citizens in a democratic society to participate in the political process by influencing who holds public office. Elections are a basic mechanism for people to engage in public affairs and to seek to influence government activities. The liberal view in political theory defines democracy as primarily representative political institutions, and voting as one of the most fundamental duties of citizens (Boyte and Kari, 2000). Rahn, Brehm, and Carlson $(1999,140)$ point out that elections also engage people "in a rite that allows them to renew their attachment to national society, particularly those people who are well informed politically and already integrated into society via membership in voluntary associations."

The goal for public affairs educators, therefore, is to identify how we might encourage students to be civically engaged, such as by advocating for some social cause, taking action for social change, participating in organizations that support their social preferences, volunteering, and voting. While service learning is one of the pedagogical tools educators use to foster civic engagement, as Battistoni (2001) notes, "civic learning does not automatically happen from a community service experience" (8). Conscious efforts have to be made on the part of educators, creating links between the students' learning and community experience and their civic engagement. Merely throwing students into community service activities without careful guidance can even create students who are as or more civically disengaged than when they started service learning activities (Battistoni, 2001).
As a way to develop an effective pedagogical strategy that fosters civic engagement among youth, we examined the factors that may lead to engaged behavior. Since the 1950s, psychologists have been studying the role of attitudinal concepts in accounting for behavior. Many researchers have suggested that attitude can be considered a predisposition to behavior (Acock and Scott, 1980;Albrecht and Carpenter, 1976). As Rokeach (1966) states, "an attitude is a relatively enduring organization of beliefs about an object or situation predisposing one to respond in some preferential manner" (530). In other words, when one's attitude toward the object or the situation is activated, it determines the behavior one would take toward the object or the situation. This attitude-behavior relationship has important implications in the development of civic engagement pedagogy. If in fact there were some attitudinal factors that induce civic engagement behaviors, identifying and examining this attitude-behavior relationship will give educators a way to identify important attitudinal factors where the educational process can make a difference.

With diverse attitudinal factors, for the purpose of this study we decided to focus on the three factors that may affect students' inclination for civic engagement: sense of citizen political control, sense of community efficacy, and awareness of diversity and social justice issues.

The first two attitudinal factors, namely, citizen control and attitude toward community efficacy are derivatives of the concept of political efficacy. Political efficacy was initially defined by Campbell, Gurin, and Miller (1954) as "the feeling that individual political action does have, or can have, an impact on the political process, that is, that it is worthwhile to perform one's civic duties" (187). This construct of political efficacy was originally proposed as a single dimension construct. However, since the 1970s, more work has been done to present more precise conceptualization of political efficacy. McPherson et al. (1977) proposed that political efficacy has two components: internal and external political efficacy. Internal political efficacy generally represents an individual's perception of the ability, resources, and 


\section{Explicating Factors That Foster Civic Engagement Among Students}

skills that are required to influence the political process; external political efficacy represents the perceptions of the responsiveness of the political system to efforts to exert influence on it.

Our measure of individual political efficacy combines internal and external efficacy into a measure of citizen control. This scale combines a traditional internal efficacy question- "Citizens like me have much to say about government" - with external measures of how responsive the government is to citizen influence and public opinion.

Complementing the control measure is a scale designed to assess the respondent's views on community efficacy. This approach follows Parisi et al. (2002), who defined community efficacy as "the ability of a local population to come together and act collectively in pursuit of a generalized interest" (19).
We decided to focus on the community rather than the general political system because of its implication to the service learning curriculum. In most service learning courses, local communities are the sites where students are engaged. We believe it is important to examine whether students' attitudes about the political efficacy of the community are associated with their civic engagement behavior.

Critics express concerns about whether democracy in the United States can survive in the face of increasing diversity and group-based social and political claims (e.g., Bloom, 1989). Willingness to engage in discourse with people who are different from themselves affects the ways in which people participate in political and civic affairs (e.g. Pang, Gay, and Stanley, 1995; Parker, 1997). Little research has empirically examined this relationship.

Figure I. Theoretical Civic Engagement Model

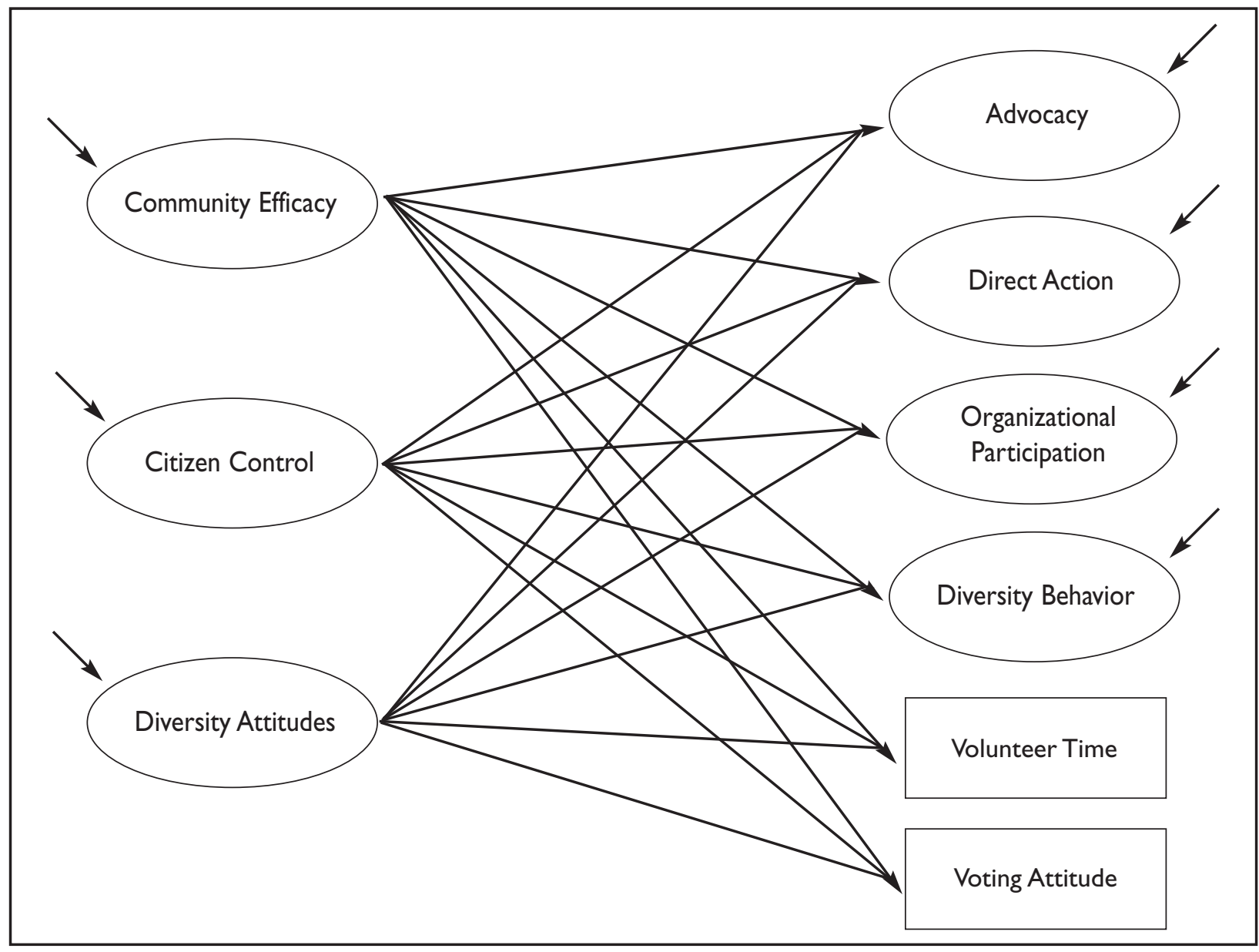




\section{Explicating Factors That Foster Civic Engagement among Students}

HYPOTHESIZED MODEL

In this study, using a structural equation model, we test the hypotheses that the attitudinal factors of community efficacy, sense of citizen control, and attitudes toward diversity are associated with the six components of civic engagement behavior: advocacy, direct action, organizational participation, taking actions to promote diversity, volunteering, and attitude toward voting.

A structural model is a formalized version of some social phenomena expressed as several interrelated theoretical propositions that link conceptual variables. Structural equation modeling allows for a systematic evaluation of the relationship of these conceptual variables (Maruyama, 1998). Figure 1 shows the theoretical model of the attitude/civic engagement behavior relationship tested in this study.

\section{Methods}

The data reported in this paper were collected in the first phase of a larger ongoing study, the Civic Capacity Initiative, funded by a three-year Department of Education grant from the Fund for Improvement of Postsecondary Education (FIPSE) (Morgan et al., 2002; Shinn et al., 2002). We surveyed students in courses selected from junior-level general education courses in the 2001-02 academic year at Portland State University, a large urban public university in the northwest United States. ${ }^{1}$ The survey was administered in a total of fifty-nine courses at the beginning of each term (twenty-two in fall, twentyone in winter, and sixteen in spring). Because some students completed the survey more than once, responses were screened to include only the surveys administered on the earliest date.

\section{Study Participants}

A total of 435 students completed the survey; ${ }^{2}$ 172 (39.5\%) male and 263 (60.5\%) female. Students' ages ranged from eighteen to sixty-eight ${ }^{3}$ and the mean age was 24.8 (median 22). The majority of the students $(362,83.2 \%)$ identified their racial background as white. Eleven international students (2.5\%) responded. Close to half of the students had at least one parent with a college degree $(210,48.3 \%)$.
Although the classes surveyed were offered as junior level courses, the level of students varied. Among the respondents, there were seven freshman (1.6\%), thirty-nine sophomores (9.0\%), 196 juniors (45.1\%), and 173 seniors (39.8\%). The ratio of the transfer students was quite high (323, 74.3\%). Appendix 1 shows the demographics of the study participants.

\section{Measures}

This paper analyzes a subset of questions in the Civic Capacity Initiative Survey that includes attitudes toward government efficacy, sense of citizen control, and social and cultural diversity and related behaviors. Three attitudinal factors-community efficacy, sense of citizen control, and diversity awareness-were measured as latent variables.

- Citizen control is a seven-item latent variable that measures how people perceive government responsiveness to public opinion, local demands, and citizen input. It captures the extent of control respondents felt over issues of concern to them. The items are derived from the General Social Survey (GSS) scale of political efficacy, as used in the 1983-87 and 1996 waves.

- The community efficacy construct is a sevenitem scale that measures how respondents evaluate the effectiveness and the efficacy of their local communities and their own abilities to respond to an issue of concern to them. The scale measures participants' perceptions of community efficacy by asking about their awareness of community efforts to make changes; their perceptions about the community's impact as a change agent; and their perception on their community's capacity for collective efficacy-i.e., coming together to act collectively in pursuit of a general interest (Parisi et al., 2002).

- The general diversity awareness construct was measured using seven items modified from Stintson's (1991) Diversity Awareness Profile scale. The seven items measure exhibited behaviors that suggest general cultural awareness. Examples include making an effort to 


\section{Explicating Factors That Foster Civic Engagement among Students}

learn about other cultures or making an effort to include members of diverse groups in both social and professional settings.

Civic engagement was operationalized with six endogenous, or dependent, variables. Four are latent variables.Appendix 2 lists the variables and latent constructs used in the analysis. Twelve items from the General Social Survey were modified and adopted to measure the first three civic engagement behaviors:

- The advocacy construct comprises five items that reflect the extent of respondent engagement in action to advocate their ideas and concerns.

- The direct action construct comprises three items that reflect the extent of respondent action to protest or boycott for their issues of concern.

- The organizational participation construct comprises four items that reflect the extent of respondent participation in activities that promote the good of an organization.

- Volunteer time was included in the model as an endogenous variable. This was a single-item observed variable measured by the number of hours reported in a typical month.

- Attitude toward voting was also measured with a single item, asking respondents to indicate the degree to which they feel voting is an obligation as a citizen.

- The diversity-related civic engagement behavior construct was measured using four items modified from Mason's (1995) "Cultural Competence Self-Assessment Questionnaire." The four items measure the extent of respondent engagement in volunteer and community activities that have direct relevance to social justice and promoting diversity.

We used demographic background variables including sex, age, income level, race, marital status, and academic year in college as control variables in the structural model. All were observed variables.
ANALYSIS

Using Mplus 2.1, structural equation modeling (SEM) was conducted in order to analyze student responses to questions on their behavior and attitudes regarding civic engagement. SEM allows for the simultaneous estimation of hypothesized relationships while generating goodness-of-fit measures to evaluate the overall fit of the hypothesized model by using an estimated covariance matrix. The advantage of SEM over traditional path analysis lies in its ability to assess the model fit and its ability to make more precise coefficient estimates by taking measurement error into account.

Results

Before testing the full structural model, we conducted a confirmatory factor analysis in order to test the measurement models for each of the seven latent constructs: the four endogenous variables of advocacy, direct action, organizational participation, and diversity-related civic engagement behavior, as well as the three exogenous variables of efficacy, citizen control, and general diversity-awareness behavior.The factor analysis demonstrated a good fit between the data and the latent constructs. The loadings were all significant and ranged from 0.41 to 0.82 . Appendix 3 shows the factor loadings and the alpha coefficient for each of the variables in the measurement model.

Next, using the full structural model, we tested the relationships between exogenous and endogenous variables, after controlling for the effects of age, household income, academic year in college, marital status, gender, and race. The covariances of exogenous variables, phi $(\Phi)$, and covariances among endogenous variables, psi $(\Psi)$ are shown in the appendix. The model has a significant chi-square $\left(X^{2}\right.$ $(867, \mathrm{~N}=435)=1464.1, \mathrm{p}<.001)$. Other fit indices that are less affected by sample size also indicate that the model is a good fit to the data (CFI $=.923$, $\mathrm{IFI}=0.924, \mathrm{SRMR}=0.049$ ).

Results are summarized in Figure 2. Expectations of community efficacy are the single most important predictor of our six categories of civic engagement. This exogenous variable is a significant predictor of 
the latent variables of advocacy, direct action, organizational participation, and diversity-related behavior. Those who believe more in the efficacy of the community and have a stronger sense of control as citizens tend to be more civically engaged. To a lesser extent, the results also suggest that college students who have a higher awareness of diversity and social justice issues tend to be more engaged. Student attitudes toward diversity are significant predictors of all the latent endogenous variables. On a narrower scale, citizen control significantly predicts advocacy, organizational participation, and voting attitudes.
The importance of self-education significantly predicts a small percentage of diversity-related behavior as well as attitudes toward voting. Of the control variables, only age, income, and race were significant predictors of the endogenous variables. Nonsignificant control variables are not reported in the model in Figure 2. Interestingly, the only negative predictors of civic engagement were household income and age. Older students were less likely to engage in diversity behavior, and those students with higher household incomes were significantly less likely to join in strikes and boycotts.

Figure I.Theoretical Civic Engagement Model

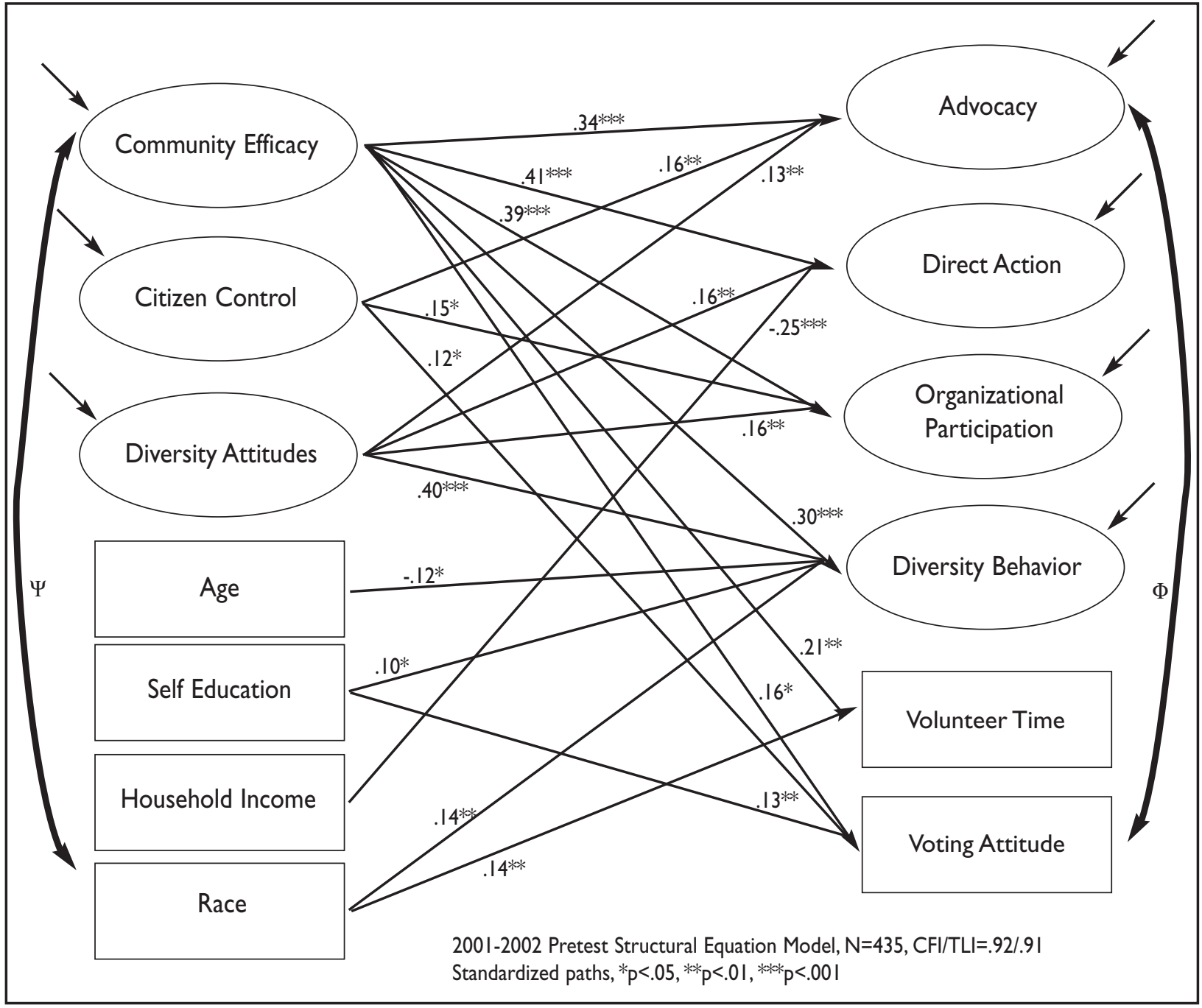




\section{Explicating Factors That Foster Civic Engagement among Students}

DisCUSSION

Various studies suggest that U.S. citizens are increasingly disengaging from political processes and communal life (Barber, 1999; Putnam, 2000; Sax, 2000; Skocpol and Fiorina, 1999). Considering the perceived lack of public interest in civic and political affairs, the findings of this study are important. This study contributes to our understanding of the connection between citizen attitudes and civic engagement behaviors. The results of the structural equation model show that those who have a stronger belief in citizen control and believe more in the efficacy of the community tend to be more civically engaged. It also suggests that college students who have higher awareness of diversity and social justice issues tend to be more engaged. To the extent that this is true, it means that we can encourage college students to be more civically engaged by trying to instill in them certain attitudes toward public life.

We found that a shared sense of control over civic issues is highly associated with being civically engaged. Therefore, the sense of control over community outcomes can promote student civic engagement, insofar as this curricular initiative succeeds at instilling this attitude of control. Based on this study's findings, we offer the following suggestions for developing courses and curricula that increase civic engagement.

Introduce success stories of civic leaders and communities to enbance the sense of citizen control and community efficacy. Paulsen (1991) advocates that education can make a difference in the students' sense of efficacy-namely, their feelings that they can accomplish what they set out to do. One way to do it in the educational setting is to introduce in classes examples of cases in which citizens in the community start taking action and successfully made a difference in society. These success stories can be easily found in the literature, including the popular media. It is not difficult to find case stories to include in course reading material (e.g., Colby et al., 2003; Putnam and Feldstein, 2003). Inviting civic leaders from the community as guest speakers is an even more vivid way of introducing students to success stories. Exposing students to different these stories is likely to help them develop positive attitudes toward citizen control and community efficacy, which may lead to them to greater civic engagement.

Provide information and opportunities for students to develop their capacity to be civic leaders. Students who do not see themselves as important social change agents as citizens typically seem to have a lack of knowledge about the social and political system. They do not actively engage in civic and political activities because they believe it is too complicated and too difficult for them to understand what is going on (Gimpel, Lay, and Schuknecht, 2003). Providing students information on how government and other political systems work can be an effective way to instill a positive attitude toward individual and community efficacy. Gerston (2002) argues that service learning is one of the most effective ways to have students learn about the policy system. This assumes explicit policy system content in the curriculum. By incorporating service learning into the study of public policy making, students "bring to life the policy making process on a personal level" (Gerston, 2002, xvii). By learning through experience, students will have a better understanding of the system, which may contribute to their development of stronger sense of control as citizens.

Expose students to diverse ideas and communities to belp them develop their diversity awareness. Gibson (2001) notes that "often overlooked in many cases [of civic engagement studies] are indicators such as a tolerance to diversity (of people and ideas)." In this study we have included diversity awareness and taking actions to promote diversity and social justice as part of our model in examining citizenship behaviors among college students. The results suggest that diversity awareness has a strong association, not only to students' diversity-related activities, but also to other civic engagement indicators. Student and young citizens who embrace diverse perspectives, exhibit empathy, and evaluate alternative options may have a better capacity to understand complex social problems and may be more inclined to participate in democratic decision 


\section{Explicating Factors That Foster Civic Engagement among Students}

making. It is also possible that those who have higher diversity awareness are the same individuals who are more aware of the importance of social injustice toward minorities and other diverse groups of people. The commitment to social justice is likely to coincide with a higher motivation to engage in civic and political activities that address social injustice.

Although the results of this study are informative and intriguing, they are not without limitations. The participants were all college students from one university and are not representative of the U.S. general population. In addition, although the total number of participants for the survey was 1,040, not all of them responded to all questions in the survey. After a listwise deletion of the missing variables, the total number of survey responses was reduced to 435 .

Although the initial examination of the missing variables did not show any apparent systematic pattern of omission, the extent of reduction in analyzable responses is a concern. It should also be noted that this study only examined a unidirectional relationship between attitudinal factors and civic engagement behaviors because of the limitation of crosssectional data. The next step for this type of research is to use longitudinal data in order to test a more comprehensive model that examines possible crosslagged causal effects between attitudes and behaviors.

\section{CONCLUSION}

This paper offers a modest contribution to the ongoing and often contentious debate about the current state of civic engagement in the United States. The Civic Capacity Initiative Survey yielded data useful for exploring the complex interrelationship between college student attitudes toward government efficacy, sense of control, diversity awareness, and civic engagement. Civic engagement in our model consists of both political and civic activities; hours spent volunteering in the community, actions taken to promote diversity, attitudes relating to the importance of voting, serving in organizations, direct actions such as protests, and finally advocacy activities such as writing letters. Our modeling results suggest that positive attitudes toward government effi- cacy, citizen control, and diversity and social justice are associated with higher levels of civic engagement. College curricula that aim to foster these attitudes in students-especially curricula emphasizing community-based learning-may expect to increase the civic engagement of young citizens.

NOTES

1. Portland State has an innovative general education program called the University Studies Program. It is a four-year general education course of study: Freshmen Inquiry is a year-long interdisciplinary thematic course by topic taught by a team of four to six faculty. In their sophomore and junior years, students pursue clusters of courses related to a theme. For the senior capstones, interdisciplinary teams of students address significant community issues.

2. Although the total number of responses for the Civic Capacity Initiative Survey was 1,090, after the listwise deletion for missing values, our sample was reduced to 435. It appears that many students did not complete the survey because of the survey's length (nine pages).

3. Undergraduate courses in this university are open to people who are over sixty-five years old through the Senior Adult Learning Center. This is probably the reason why we had some respondents who are over sixty-five years of age.

\section{REFERENCES}

Acock,A. C., and W. J. Scott. 1980. "A Model for Predicting Behavior:The Effect of Attitude and Social Class on High and Low Visibility Political Participation." Social Psychology Quarterly, 43(1):59-72.

Albrecht, S. L., and K. E. Carpenter. 1976. "Attitudes as Predictors of Behavior Versus Behavior Intentions:A Convergence of Research Traditions." Sociometry, 39(1):1-10.

Alt, N., and E. Medrich. 1994. "Student Evaluation in Community Services." Paper prepared for the U.S. Department of Education, Office of Research. Berkeley, CA: MPR Associates.

Barber, B. 1999. A Place for Us: How to Make Society Civil and Democracy Strong. NJ: Princeton University Press.

Battistoni, R. M. 1997. "Service Learning and Democratic Citizenship." Theory into Practice, 36(3):150-157.

Battistoni, R. M. 2001. Civic Engagement Across the Curriculum:A Resource Book for Service Learning Faculty in All Disciplines. Providence, RI: Campus Compact.

Bloom,A. 1987. The Closing of the American Mind. New York: Simon and Schuster.

Boyte, H. C., and J. Farr. 1997. "The Work of Citizenship and the Problem of Service Learning." In R. M. Battisoni and W. E. Hudson, eds., Experiencing Citizenship: Concepts and Models for Service Learning in Political Science. Washington, D.C.:American Association for Higher Education.

Boyte, H. C., and N. C. Kari. 2000."Renewing the Democratic Spirit in American Colleges and Universities." In T. Ehrlich, ed., Civic Responsibility and Higher Education. Phoenix,AZ:American Council on Education and the Oryx Press, 37-59.

Bok, D. 2001. The Trouble with Government. Cambridge, MA: Harvard University.

Campbell,A., G. Gurin, and W. Miller. 1954. The Voter Decides. Evanston, IL: Row, Peterson. 


\section{Explicating Factors That Foster Civic Engagement Among Students}

Checkoway, B. 2001. "Renewing the Civic Mission of the American Research University." Journal of Higher Education, 72(2):125-147.

Colby,A., et al. 2003. Educating Citizens: Preparing America's Undergraduates for Lives of Moral and Civic Responsibility. San Francisco: Jossey-Bass.

Dicke, L., S. Dowden, and J.Torres. 2004. "Successful Service Learning:A Matter of Ideology. Journal of Public Affairs Education, 10(3):199 208.

Ehrlich,T. 2000. Civic Responsibility and Higher Education. Phoenix,AZ: American Council on Education and the Oryx Press.

Gerston, L. N. 2002. Public Policy-Making in a Democratic Society. New York: M. E. Sharpe.

Gibson, C. 2001. "From Inspiration to Participation:A Review of Perspectives on Youth Civic Engagement." Grantmaker Forum on Community and National Service. Berkeley: CA.

Gimpel, J. G., J. C. Lay, and J. E. Schuknecht. 2003. Cultivating Democracy: Civic Environments and Political Socialization in America. Washington, D.C.: Brookings Institution.

Hamilton, S., and R. Zeldin. 1987."Learning Civics in the Community." Curriculum Inquiry, 17(4):407-420.

Keeter, S., et al. 2002. The Civic and Political Health of the Nation:A Generational Portrait. Available at www.puaf.umd.edu/CIRCLE/ research/products/Civic_and_Political_Health.pdf.

Maruyama, G. M. 1998. Basics of Structural Equation Modeling. Thousand Oaks: Sage.

Mason, J. L. 1995. Cultural Competence Self-Assessment Ouestionnaire: A Manual for Users. Portland, OR: Portland State University, Research and Training Center on Family Support and Children's Mental Health, Regional Research Institute for Human Services.

McPherson, J., et al. 1977. "The Stability and Reliability of PE: Using Path Analysis to Test Alternative Models." American Political Science Review, 71:509-521.

Morgan, D., et al. 2002. "Civic Capacity Initiative: Integrating Liberal Arts and Professional/Career Education." Poster session presented at Campus Compact Continuums of Service Western Regional conference, Portland, Oregon

Myers-Lipton, S. J. 1999. "Effect of a Comprehensive Service Learning Program on College Students' Civic Responsibility." Teaching Sociology, 26:243-258.

Pang V. O., G. Gay, and W. B. Stanley. 1995. "Expanding Conceptions of Community and Civic Competence for a Multicultural Society.' Theory and Research in Social Eduction, 23(4):302-331.

Parisi, D., et al. 2002. "Building Capacity for Community Efficacy for Economic Development in Mississippi." Journal of the Community Development Society, 33(2):19-38

Parker,W. C. 1997. "Democracy and Difference." Theory and Research in Social Education, 220-234.

Paulsen, R. 1991. "Education, Social Class, and Participation in Collective Action." Sociology of Education, 64:96-110.

Putnam, R. D. 2000. Bowling Alone. New York: Simon and Schuster.

Putnam, R. D., and L. Feldstein. 2003. Better Together: Restoring the American Community. New York: Simon and Schuster

Rahn,W. M., J. Brehm, and N. Carlson. 1999."National Election and Social Capital." In T. Skocpol and M. Fiorina, eds., Civic Engagement in American Democracy, 111-141. Washington, D.C.: Brookings Institution.

Rokeach, M. 1966. "Attitude Change and Behavioral Change." The Public Opinion Quarterly, 30(4):529-550.

Rothstein, R. 2001. "What Produces a Voter? Seemingly Not Civics Class." New York Times, July 11, B10.
Sax, L. 2000. "Citizenship Development and the American College Students.” In T. Ehrlich, ed., Civic Responsibility and Higher Education. Phoenix,AZ: American Council on Education and the Oryx Press.

Shinn, C., et al. "How Do We Measure the Impact of Service Learning Courses on Students' Development of Civic Capacity?" Paper presented at Campus Compact Continuums of Service Western Regional conference, Portland, Oregon.

Skocpol,T., and M. Fiorina, eds. 1999. Civic Engagement in American Democracy. Washington, D.C.: Brookings Institution.

Skocpol,T. 1999. "Advocates Without Members: The Recent Transformation of American Civic Life." In T. Skocpol and M. Fiorina, eds., Civic Engagement in American Democracy. Washington, D.C. Brookings Institution, 461-509

Skocpol,T. 2003. Diminished Democracy: From Membership to Management in American Civic Life. Norman, OK: University of Oklahoma.

Stintson, K. 1991. Diversity Awareness Profile. Hoboken, NJ: Pfeiffer Wuthnow, R. 1998. Loose Connections: Joining Together in America's Fragmented Communities. Cambridge: Harvard University Press. 
Appendix I

Summary of Demographic Background of Students Who Responded to the Survey

$\begin{array}{lcc}\text { Categories } & N & (\%) \\ & (435) & \\ \begin{array}{l}\text { Gender } \\ \text { Male }\end{array} & \\ \quad \text { Female } & 172 & 39.5 \\ & 263 & 60.5 \\ \text { Race } & & \\ \text { White } & 362 & 83.2 \\ \quad \text { Nonwhite } & 73 & 16.8 \\ \quad & \\ \text { International students } & & \\ \text { International students } & 11 & 2.5 \\ \quad & & \\ \text { Parent's educational background } & & \\ \quad \text { High school diploma/GED } & 225 & 51.7 \\ \text { Bachelor degree } & 109 & 25.1 \\ \text { Advanced degree } & 101 & 23.2\end{array}$

Household income

Mean income $\$ 30,000$

$\$ 39,999$

Academic level

Freshman

Sophomore

$\begin{array}{ll}7 & 1.6\end{array}$

Junior

$39 \quad 9.0$

Senior

216

49.6

$173 \quad 39.8$

Transfer status

Transfer student

$323 \quad 74.3$

Non transfer student

$112 \quad 25.7$

Note: Mean age 24.8, median 22, range I8-68. 


\section{Appendix 2. List of Variables and Latent Constructs Used in the Analysis}

Advocacy

- Contacted government officials on behalf of the organization.

- Written a congress person, senator, or local commissioner.

- Written a letter to the local newspaper.

- Written an article for magazine or newspaper.

- Written to newspapers or magazines for the organization.

\section{Direct Action}

- Attended lawful demonstration.

- Joined unofficial strikes.

- Joined boycotts.

\section{Community Efficacy}

- In an issue of concern to you, are you aware of efforts by the community to make changes?

- In the issue of concern to you, as well as others, are you aware of efforts by the community to make changes?

- How successful have these efforts been in making changes?

- Can people in your community make a difference in the issue of concern to you?

- How likely to get involved in the community?

- What level of ability does your community have to make a change?

- What level of ability do you have to address the issue of concern to you?

\section{Organizational Participation}

- Served on committees.

- Served as an officer.

- Given money in addition to regular dues.

- Attended conferences or workshops.

\section{Citizen Control}

- Citizens have influence on politics.

- Citizens have a great deal of influence on government decisions.

- Government is responsive to public opinion.

- Citizens control over politicians.

- Citizens can get somewhere by talking to public officials.

- Citizens influence running local government.

- Citizens can control world affairs.

\section{General Diversity Awareness Behaviors}

- Encourage members of minority groups to speak out on their issues and concerns and treat those issues as valid.

- Keep all others, including members of minority group, in formal and informal information group.

- Planned or encouraged social events in which all people are able to participate.

- Take responsibility for helping new people in my organization (work, school) including women and people of various cultures, ages, and sizes, to feel welcome and accepted.

- Include members of minority groups, in the informal networks and/or social events.

- Assume and convey the message that members of minority groups are as skilled and competent as others.

- Make extra efforts to educate myself about other cultures. 


\section{Appendix 2. List of Variables and Latent Constructs Used in the Analysis (continued)}

Diversity-related Civic Engagement Behavior

- Attend community forums or neighborhood meetings within communities of minority group.

- Attend community-or culturally-based advocacy group meetings within minority group committees.

- Call, write, or in some ways protest when a book, newspaper, television show, or some branch of media perpetuates or reinforces a bias or prejudice.

- Participate in volunteer or community activities that are making efforts in changing the society?

The Importance of Self Education

- Keeping fully informed about news and public issues.

Volunteer Time

- Number of hours volunteered in a typical month.

Attitude Toward Voting

- Voting in election is an obligation that a citizen owes the country.

Background Information

- Age

- Household income (coded in 13 categories with the lowest category being 'less than $\$ 5,000$ '; highest category being ' $\$ 1,000,000$ or more')

- Academic year in college (coded 'l' for juniors and seniors and ' 0 ' for freshman, sophomores, and others),

- Marital status (coded ' $I$ ' for married and ' 0 ' for all the other marital status)

- Gender (coded ' $I$ ' for female and ' 0 ' for male

- Race(coded 'I' for all minority categories and '0' for white). 


\section{Appendix 3. Factor Loadings and Alpha Coefficient for Each Measure}

Survey Items

\section{Advocacy}

Contacted government officials on behalf of the organization

Written a congress person, senator, or local commissioner

Written a letter to the local newspaper

Written an article for magazine or newspaper

Written to newspapers or magazines for the organization

\section{Direct Action}

Attended lawful demonstration

Joined unofficial strikes

Joined boycotts

\section{Organizational Participation}

Served on committees

Served as an officer

Given money in addition to regular dues

Attended conferences or workshops

\section{General Diversity Attitudes}

Encourage members of minority groups to speak out on their issues and concerns and treat those issues as valid.

Keep all others, including members of minority group, in formal and informal information group.

Planned or encouraged social events, in which all people are able to participate.

Take responsibility for helping new people in my organization

(work, school) including women and people of various cultures,

ages, and sizes, to feel welcome and accepted.

Include members of minority groups, in the informal networks

and/or social events

Assume and convey the message that members of minority groups

are as skilled and competent as others.

Make extra efforts to educate myself about other cultures.

Diversity-related Civic Engagement Behavior

Attend community forums or neighborhood meetings within communities of minority group.

Attend community-or culturally-based advocacy group meetings

within minority group committees.

Call, write, or in some ways protest when a book, newspaper,

television show, or some branch of media perpetuates or

reinforces a bias or prejudice.

Standardiz
Loading

.746
.641
.682
.651
.764

.820

.727

.753

.731

.613

.483

.718

.788

.817

.766

.686

.753

.623

.615

Participate in volunteer or community activities that are

making efforts in changing the society?
.810 


\section{Appendix 3. Factor Loadings and Alpha Coefficient for Each Measure (continued)}

Survey Items

\section{Citizen Control}

Citizens have considerable influence on politics.

Citizens have a great deal of influence on government decisions.

Government is generally responsive to public opinion.

Citizens have control over what politicians do in office.

Citizens can get somewhere by talking to public officials.

Citizens have much to say about running local government.

By taking an active part in political and social affairs, citizens can

control world affairs.

\section{Community Efficacy}

In an issue of concern to you, are you aware of efforts by the community to make changes?

In the issue of concern to you, as well as others, are you aware of efforts by the community to make changes?

How successful have these efforts been in making changes?

Can people in your community make a difference in the issue of concern to you?

How likely to get involved in the community?

What level of ability does your community have to make a change?

What level of ability do you have to address the issue of concern to you?
Standardized Standardized

Loading Alpha

.894

.827

.816

.680

.784

.779

.676

.606

.725

.589

.537

.511

.531

.552

.418

.451 


\section{Appendix 4. Phi ( $\Phi)$ and Psi ( $\Psi)$ Coefficients}

Phi (Ф) coefficient

$\begin{array}{ll}\text { Diversity Awareness } \quad \text { Control } & \begin{array}{l}\text { Expectations } \\ \text { and Efficacy }\end{array}\end{array}$

Diversity Awareness

Citizen Control

$$
.095
$$

Community Efficacy

$.225^{* * * *}$ $.299 * * *$

Self Education

$.185^{* * * *}$

Sex

$.298^{* * * *}$

Marital Status

.012

$.125 *$

$.239 * * *$

Age

.073

.031

$.243^{* * *}$

Income Level

$-.022$

.079

$-.006$

Race

.054

.026

.027

.131 ***

$-.037$

Academic Year

$-.002$

.033

$-.074$

$-.018$

.029

${ }^{*} \mathrm{p}<.05,{ }^{*} \mathrm{p}<.01, * * * \mathrm{p}<.001$

\section{Psi ( $\Psi)$ coefficients}

$\begin{array}{ccccc}\text { Advocacy } & \text { Direct } & \text { Org. } & \text { Volunteer } & \text { Voting } \\ & \text { Action } & \text { Participation } & \text { Time } & \text { Attitude }\end{array}$

Advocacy

Direct Action

$.452 * * *$

Org.Participation

$.534 * * * *$

$.298 * * *$

Volunteer Time

$.213^{* * *}$

.063

$.312^{* * * *}$

Voting Attitude

$-.022$

$-.016$

.059

.009

Diversity Behavior

$.330 * * *$

$.225 * * *$

$.355 * * *$

$.227^{* * *}$

${ }^{*} \mathrm{p}<.05,{ }^{*} *_{\mathrm{p}}<.01,{ }^{*} *_{\mathrm{p}}<.001$ 
Explicating Factors That Foster Civic Engagement among Students

Masami Nishishiba is an assistant professor of public administration in the Mark O. Hatfield School of Government at Portland State University. Her research and publication interests include issues of social diversity, civic capacity, and quantitative methods.

Hal T. Nelson is a doctoral candidate and an instructor in the Mark O. Hatfield School of Government at Portland State University. His research interests are civic engagement, international political economy, and energy policy.

Craig W. Shinn is an associate professor and a division chair of public administration in the Mark O. Hatfield School of Government at Portland State University. He has a broad teaching, research, and civic career in land and public use planning, as well as natural resources policy, organization, and management. 